\title{
Clinical features of 2019 novel coronavirus infection in Beijing
}

\author{
Yan Li, Shengyong Xu, Tiekuan Du, Jun Xu, Yi Li, Xuezhong Yu, Huadong Zhu \\ Department of Emergency Medicine, Chinese Academy of Medical Sciences, Peking Union Medical College Hospital, Beijing 100730, China \\ Contributions: (I) Conception and design: H Zhu, Y Li, X Yu, J Xu, Y Li; (II) Administrative support: H Zhu, X Yu, J Xu, Y Li; (III) Provision of study \\ materials or patients: Y Li, S Xu, T Du; (IV) Collection and assembly of data: Y Li, S Xu, T Du; (V) Data analysis and interpretation: Y Li, S Xu, T \\ Du; (VI) Manuscript writing: All authors; (VII) Final approval of manuscript: All authors. \\ Correspondence to: Huadong Zhu, MD. Department of Emergency Medicine, Peking Union Medical College Hospital, No.1 Shuaifuyuan Wangfujing, \\ Dongcheng District, Beijing 100730, China. Email: huadongzhu@hotmail.com.
}

Background: A new coronavirus pneumonia caused by 2019 new coronavirus (2019-nCoV) is spreading in China. Here we summarized the patients we accepted in the fever outpatient department.

Methods: Patients with epidemiologic history, respiratory symptoms or fever were required to go to the fever clinic for screening. Patients were finally laboratory-confirmed 2019-nCoV infection by real-time reverse transcription-polymerase chain reaction (RT-PCR) using nasal and pharyngeal swabs. Epidemiologic features, clinical presentation, laboratory findings and image features were collected and analyzed.

Results: Totally, 16 patients were diagnosed as $2019-\mathrm{nCoV}$ infection. The median age of the patients was 39.00 (35.25-55.75) years old, and the ratio of men and women was 9:7. Fifteen (93.75\%) patients had clear epidemiologic history. The most common symptoms of the patients were fever $(87.50 \%)$ and cough ( $\mathrm{n}=8$, $50.00 \%)$. The mean white blood cell count in the patients was $(4.97 \pm 1.71) \times 10^{\%} / \mathrm{L}$, and it was lower than $4.00 \times 10^{9} / \mathrm{L}$ in $4(25.00 \%)$ patients. The median neutrophil and lymphocyte count were $2.70(1.84-3.27)$ $\times 10^{9} / \mathrm{L}$ and $(1.52 \pm 0.53) \times 10^{9} / \mathrm{L}$ respectively. The mean C-reactive protein level was $19.11 \pm 17.39 \mathrm{mg} / \mathrm{L}$. Patients were likely had normal procalcitonin, creatinine, alanine aminotransferase, creatine kinase and lactate dehydrogenase levels at diagnosis. Fourteen (87.50\%) patients had pneumonia in chest CT scan.

Conclusions: No specific symptom was helpful in the diagnosis of 2019-nCoV infection, but relatively low WBC and lymphocyte level might be suggestive to diagnosis. Most patients had fever and pneumonia, however, there were indeed some patients without fever and pneumonia. Screening procedure should not only focus on fever patients. The origin, transmission route, key targets of the virus and mechanism of infection deserved more studies.

Keywords: 2019 new coronavirus (2019-nCoV); pneumonia; fever

Submitted Feb 16, 2020. Accepted for publication Feb 25, 2020.

doi: $10.21037 /$ jtd.2020.03.33

View this article at: http://dx.doi.org/10.21037/jtd.2020.03.33

\section{Introduction}

Since December 2019, many cases of pneumonia with unknown causes have been found in Wuhan, Hubei Province. It is now recognized as new coronavirus pneumonia, and its pathogen is a new coronavirus strain that has not been found in human body previously $(1,2)$. It is named as 2019 new coronavirus, namely "2019-nCoV". Even though it was first found in Wuhan, it spreads rapidly all over the country, even to whole world (3-7). However, the origin, variation, population susceptibility, disease prevalence, and clinical spectrum of the infection are not clear. Here we summarized the patients we accepted in the fever outpatient department of Peking Union Medical College Hospital.

\section{Methods}

\section{Data collection}

In order to strictly control the development of the epidemic situation, except for the patients with fever, patients with epidemiologic history (there was a history of travel 
or residence in Wuhan and its surrounding areas and communities with reported cases within 2 weeks before the onset of the disease; or within 14 days before the onset of the disease, contacted with 2019-nCoV infection patients (with positive nucleic acid test); or within 14 days before the onset of the disease, contacted with patients with fever and respiratory symptoms from Wuhan and its surrounding areas and communities with reported cases; or there was clustering onset of disease) (8) or respiratory symptoms (such as cough and dyspnea) were required to go to the fever clinic for screening the 2019-nCoV infection. Nasal and pharyngeal swabs were tested for influenza and 2019-nCoV nucleic acid by Laboratory of Peking Union Medical College Hospital. Patients were finally laboratory-confirmed 2019-nCoV infection by real-time reverse transcription-polymerase chain reaction (RT-PCR). Epidemiologic features, clinical presentation, laboratory findings and image features of the $2019-\mathrm{nCoV}$ infection patients visited at January 19, 2020 to February 12, 2020 were collected and analyzed. This study was approved by the institutional review board committee of Peking Union Medical College Hospital (No. S-K1041) and informed consent was taken from all the patients.

\section{Statistics}

Statistical analysis was finished by SPSS Statistics 17.0. The normality of the distribution was assessed using the Kolmogorov-Smirnov test. Data are shown as means \pm $\mathrm{SD}$ or median $(25-75 \%)$. The $\mathrm{P}$ value less than 0.05 was considered to be significant.

\section{Results}

\section{Demographic characteristics and epidemiologic features of the patients}

Totally, 16 patients were diagnosed as 2019-nCoV infection by real-time RT-PCR. The median age of the patients was 39.00 (35.25-55.75) years, and only one of them was younger than 18 years old whose age was 7 years old. The ratio of men and women was 9:7. Ten $(62.50 \%)$ patients travelled or resided in Wuhan within two weeks of onset. Only one of them had Huanan seafood market exposure history. Except 3 patients got fever in Wuhan, the median days of leaving Wuhan to onset were 4.00 (2.00-9.00) and the longest one was 13 days; 6 (37.50\%) patients had contact history with 2019$\mathrm{nCoV}$ infection patients within 2 weeks; 9 (56.25\%) patients had clustering onset, 6 of them were 3 couples and 1 of them was the child of one couple; $1(6.25 \%)$ patient had no clear epidemiologic history. Most (93.75\%) of the patients had no comorbidities except one of them had emphysema (Table 1).

\section{Clinical features of the screened patients}

The most common symptom of the patients was fever $(n=14$, $87.50 \%$ ), and the median highest temperature was $38.00{ }^{\circ} \mathrm{C}$ $\left(37.65-38.55^{\circ} \mathrm{C}\right)$ in which the lowest one was $37.30{ }^{\circ} \mathrm{C}$. Less common manifestations were cough $(\mathrm{n}=8,50.00 \%)$, myalgia or fatigue $(n=6,37.50 \%)$, rhinorrhea $(n=5,31.25 \%)$, sputum $(n=4,25.00 \%)$ and pharyngalgia $(n=4,25.00 \%)$. Only small part of the patients had dyspnea $(n=2,12.50 \%)$, headache $(\mathrm{n}=2,12.50 \%)$ and diarrhea $(\mathrm{n}=1,6.25 \%)$. The median days from onset to visit were 3.00 (2.00-5.00). The pulse oxygen saturation in the patients was $98.00 \% \pm 1.63 \%$, and it was $95 \%$ and $98 \%$ respectively in two patients who had dyspnea. The median days from onset to visit were 3.00 (2.00-5.00). None of the patients had rales in lung in physical examination (Table 1).

\section{Laboratory findings and image features of the screened patients}

The mean white blood cell (WBC) count in the patients was $(4.97 \pm 1.71) \times 10^{9} / \mathrm{L}$, and it was lower than $4.00 \times 10^{9} / \mathrm{L}$ in $4(25.00 \%)$ patients and higher than $10.00 \times 10^{9} / \mathrm{L}$ in $1(6.25 \%)$ patient. The median neutrophil (NEUT) count was $2.70(1.84-3.27) \times 10^{9} / \mathrm{L}$, and it was lower than $2.00 \times 10^{9} / \mathrm{L}$ in $4(25.00 \%)$ patients. The mean lymphocyte (LY) count was $(1.52 \pm 0.53) \times 10^{9} / \mathrm{L}$ and only $1(6.25 \%)$ patient had a LY count lower than $0.80 \times 10^{9} / \mathrm{L}$. The mean hemoglobulin and platelet count were $145.38 \pm 22.39 \mathrm{~g} / \mathrm{L}$ and $(205.25 \pm 56.63)$ $\times 10^{9} / \mathrm{L}$ respectively. The mean $\mathrm{C}$-reactive protein level was $19.11 \pm 17.39 \mathrm{mg} / \mathrm{L} ; 14(87.50 \%)$ patients had a negative procalcitonin level that was less than $0.072 \mathrm{ng} / \mathrm{mL}$, and the highest level was $0.12 \mathrm{ng} / \mathrm{mL}$ in other 2 patients. The mean creatinine (Cr) level was $76.81 \pm 20.10 \mu \mathrm{mol} / \mathrm{L}$. The median creatine kinase (CK) level was 77.00 (56.00-167.00) U/L. The mean alanine aminotransferase (ALT) level was $21.63 \pm 14.08 \mathrm{U} / \mathrm{L}$ and only $2(12.50 \%)$ patients had mildly elevated ALT level. The median lactate dehydrogenase (LD) level was 169.00 (140.00-224.50) U/L, only 1 (6.25\%) of them had a level higher than $250 \mathrm{U} / \mathrm{L}$ (Table 2). Three of them underwent 2019-nCoV immunoglobulin $\mathrm{M}$ ( $\operatorname{IgM})$ test, and 2 of them were positive. They visited at $1^{\text {st }}$ and $2^{\text {nd }}$ day after onset respectively. The other one had negative serum 2019-nCoV IgM, and he visited at $4^{\text {th }}$ day after onset. None 
Table 1 Demographic, epidemiologic and clinical features of 2019$\mathrm{nCoV}$ infection patients

\begin{tabular}{|c|c|}
\hline Characteristics & $\begin{array}{l}\text { 2019-nCoV patients } \\
\qquad(\mathrm{n}=16)\end{array}$ \\
\hline Age, years & $39.00(35.25-55.75)$ \\
\hline \multicolumn{2}{|l|}{ Sex } \\
\hline Men & $9(56.25 \%)$ \\
\hline Women & $7(43.75 \%)$ \\
\hline \multicolumn{2}{|l|}{ Epidemiologic features (within 2 weeks) } \\
\hline Travel or residence in Wuhan & $10(62.50 \%)$ \\
\hline Days from leaving Wuhan to onset & $4.00(2.00-9.00)^{\star}$ \\
\hline $\begin{array}{l}\text { Contact with } 2019-n C o V \text { infection } \\
\text { patients }\end{array}$ & $6(37.50 \%)$ \\
\hline Clustering onset & $9(56.25 \%)$ \\
\hline No epidemiological contact history & $1(6.25 \%)$ \\
\hline \multicolumn{2}{|l|}{ Comorbidities } \\
\hline Emphysema & $1(6.25 \%)$ \\
\hline No & $15(93.75 \%)$ \\
\hline \multicolumn{2}{|l|}{ Symptoms } \\
\hline Fever & $14(87.50 \%)$ \\
\hline Highest temperature, ${ }^{\circ} \mathrm{C}$ & $38.00(37.65-38.55)$ \\
\hline Cough & $8(50.00 \%)$ \\
\hline Sputum & $4(25.00 \%)$ \\
\hline Pharyngalgia & $4(25.00 \%)$ \\
\hline Rhinorrhea & $5(31.25 \%)$ \\
\hline Myalgia or fatigue & $6(37.50 \%)$ \\
\hline Headache & $2(12.50 \%)$ \\
\hline Dyspnea & $2(12.50 \%)$ \\
\hline Diarrhea & $1(6.25 \%)$ \\
\hline Days from onset to visit & $3.00(2.00-5.00)$ \\
\hline \multicolumn{2}{|l|}{ Physical examination } \\
\hline Pulse oxygen saturation, $\%$ & $98.00 \pm 1.63$ \\
\hline Rales in lung, & $0(0 \%)$ \\
\hline
\end{tabular}

*, $n=7$.

of the patients had positive influenza A or B nucleic acid test.

Fourteen $(87.50 \%)$ patients had pneumonia in chest CT scan, in which $13(92.86 \%)$ of them showed ground-glass opacity and 1 (7.14\%) of them showed consolidation (Figure 1).
Two $(12.50 \%)$ patients has normal chest CT scan, one of them was a 36-year-old female and the other one was a 7 -year-old male. The days from onset to visit were 1 and 2 days respectively. None of them had other symptoms such as cough, sputum, pharyngalgia, rhinorrhea and so on except fever. The highest temperature was $37.5^{\circ} \mathrm{C}$ and $37.8^{\circ} \mathrm{C}$ respectively. Also, they had normal complete blood count, Cr, CK, ALT, LD and PCT levels.

\section{Discussion}

In this study, the age of the patients ranged from 7 to 68 , the median of which was $39 ; 6.25 \%$ of the patients were younger than 18 years old; $56.25 \%$ of the patients were males. And $93.75 \%$ of the patients had no comorbidities. Not like previously reported that the virus was more likely to affect older males with comorbidities (9), no specific population susceptibility in people of different age, genders and comorbidities was found. Only $6.25 \%$ of the patients reported Huanan seafood market exposure history, where the first case was found (10). And $43.75 \%$ of the patients in this study had familial clustering onset, as other studies found (11). This study provided further evidence for humanto-human transmission of 2019-nCoV. The median days of leaving Wuhan (potential exposure) to onset were 4.00 (2.00-9.00) and the longest one was 13 days. It confirmed a long incubation period of the virus infection (10).

In concert with other studies $(9,10)$, the most common symptoms of the patients were fever and cough. This study reported 2 patients without fever visited because of cough, sputum or pharyngalgia. Also, previous study reported patients without fever (10). It was not safe to let a person without fever but with epidemiologic history and respiratory symptoms go without screening. Upper respiratory tract symptoms such as pharyngalgia and rhinorrhea were not that rare. And different from the previously reported diagnosis method $(10,12)$, all the patients of this study were diagnosed with nasal and pharyngeal swabs, so the route of transmission and location of invasion need more research. $6.25 \%$ of the patients had diarrhea in this study, even though not that common as that in Severe Acute Respiratory Syndrome coronavirus (SARS-CoV) and Middle East Respiratory Syndrome coronavirus (MERS-CoV) infection $(13,14)$, further studies should be performed to determine other potential routes of transmission such as excrement and urine. In this study, none of the patients had rales in lung, so negative physical examination of respiratory system had no value in excluding patients. $25 \%$ 
Table 2 Laboratory findings and image features of 2019-nCoV patients

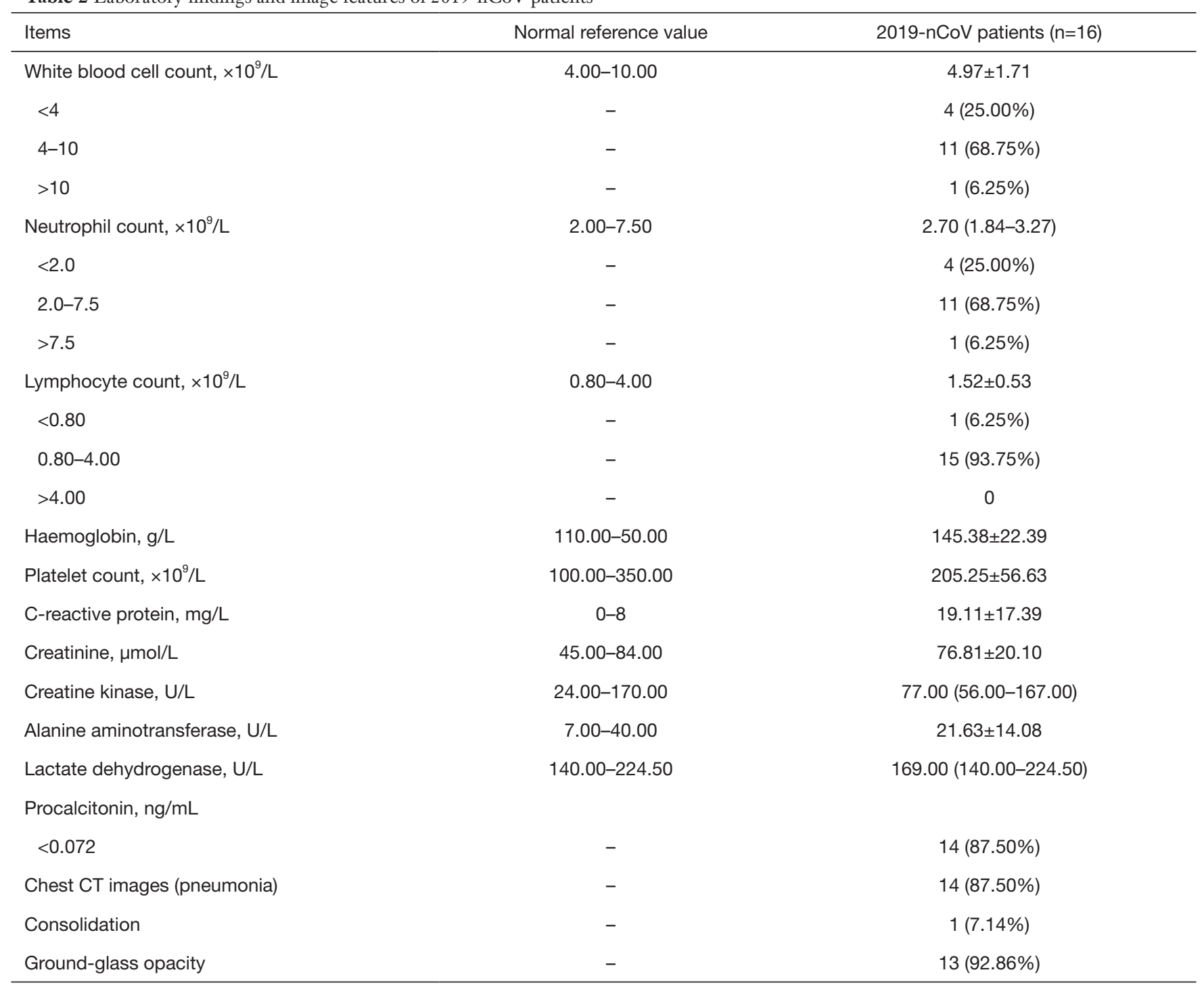

of the patients in this study had a WBC level lower than $4.00 \times 10^{9} / \mathrm{L}$, however, lymphocyte count was not that low as previously reported $(9,10)$. It was possibly because that the lower limit of normal value and the patients' condition were different among different studies. No obvious abnormalities in other blood test such as Cr, ALT, CK, CRP and PCT were found in 2019-nCoV infected patients. It was different from previous studies (15). This might due to the relatively lighter in severity of the patients included in the study. Two in 3 of nucleic acid positive patients had positive serum IgM test, while 1 patient was negative. And there was no difference in time from onset to visiting. The diagnosis value of serum 2019-nCoV IgM deserved more studies.
$87.50 \%$ patients had pneumonia in chest CT scan. It was higher than previous reported (15). But it said that negative chest CT scan could not be used to exclude 2019-nCoV infection if the epidemiologic history, symptoms and blood test supported infection. In this study, the days from onset to visit was only 1 to 2 days which was relatively short in patients with normal chest CT scan. When the patients' condition worsened, pulmonary imaging should be reexamined to determine whether pneumonia occurred.

There are some limitations in this study. First, it enrolled only 16 patients in the study. It might be not enough to get the final conclusion. Second, only nasal and pharyngeal swabs were used in diagnosis. It was 

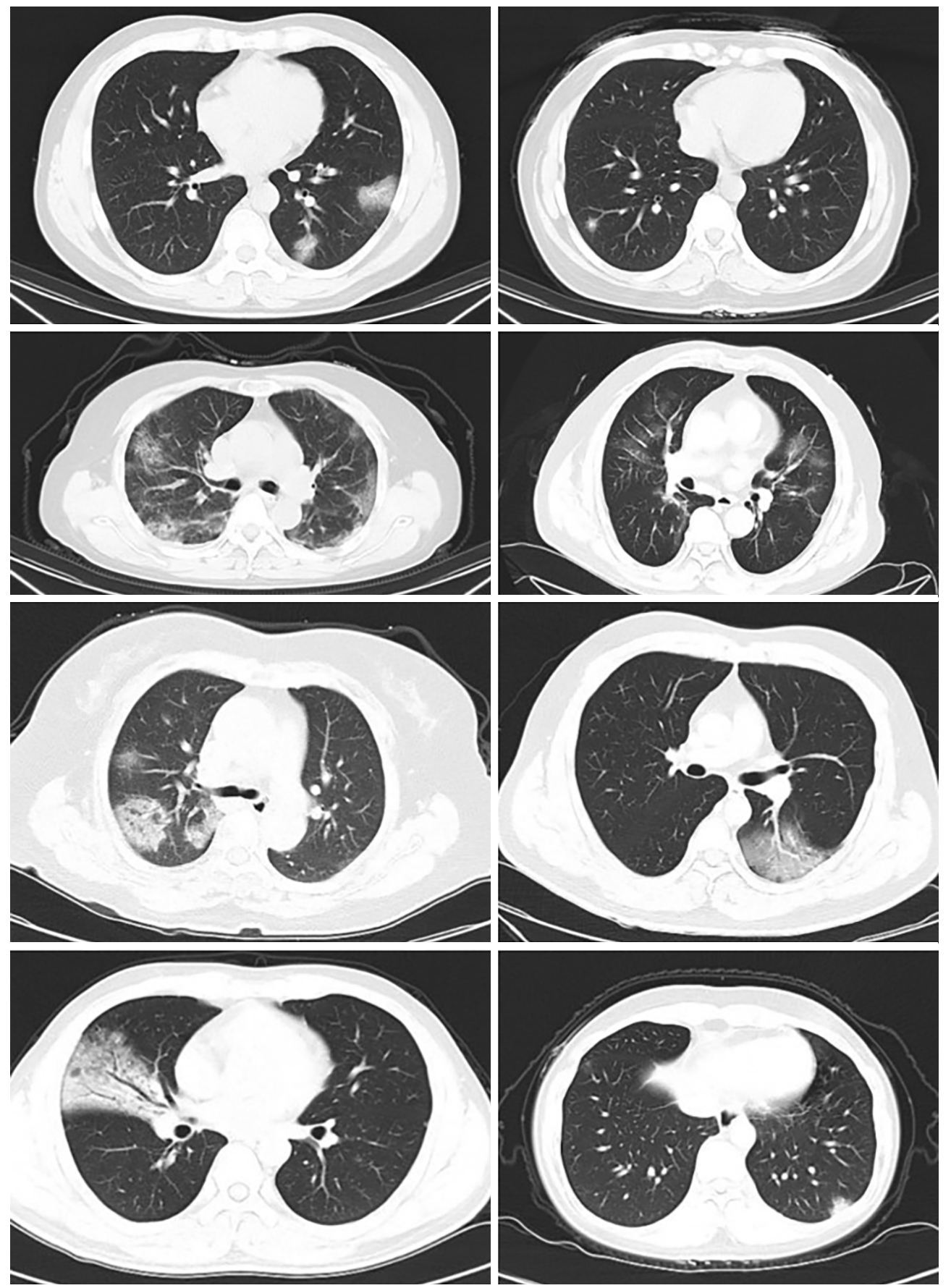

Figure 1 The image characteristics of 2019-nCoV infection patients.

impossible to investigate the difference in diagnosis between upper and lower respiratory tract specimens and to provide some information for the location of invasion of 2019-nCoV. Third, none of the patients had respiratory failure in this study, the presentation of these patients was not that good.

\section{Conclusions}

No specific symptom was helpful in the diagnosis of 2019$\mathrm{nCoV}$ infection, but low WBC and lymphocyte level might be suggestive to diagnosis. Most patients had fever and pneumonia, however, there were indeed some patients 
without fever and pneumonia. Screening procedure should not only focus on fever patients. The origin, transmission route, key targets of the virus and mechanism of infection deserved more studies.

\section{Acknowledgments}

Funding: None.

\section{Footnote}

Conflicts of Interest: All authors have completed the ICMJE uniform disclosure form (available at http://dx.doi. org/10.21037/jtd.2020.03.33). The authors have no conflicts of interest to declare.

Ethical Statement: The authors are accountable for all aspects of the work in ensuring that questions related to the accuracy or integrity of any part of the work are appropriately investigated and resolved. This study was approved by the institutional review board committee of Peking Union Medical College Hospital (No. S-K1041) and informed consent was taken from all the patients.

Open Access Statement: This is an Open Access article distributed in accordance with the Creative Commons Attribution-NonCommercial-NoDerivs 4.0 International License (CC BY-NC-ND 4.0), which permits the noncommercial replication and distribution of the article with the strict proviso that no changes or edits are made and the original work is properly cited (including links to both the formal publication through the relevant DOI and the license). See: https://creativecommons.org/licenses/by-nc-nd/4.0/.

\section{References}

1. Munster VJ, Koopmans M, van Doremalen N, et al. A Novel Coronavirus Emerging in China - Key Questions for Impact Assessment. N Engl J Med 2020;382:692-4.

2. WHO. Novel coronavirus - China. Jan 12, 2020. Available online: http://www.who.int/csr/don/12-january-2020novel-coronavirus-china/en/

3. National Health Commission of People's Republic of China. Epidemic update and risk assessment of 2019 Novel Coronavirus. Jan 28, 2020. Available online: http://www. chinacdc.cn/yyrdgz/202001/P020200128523354919292.pdf

4. WHO. Novel coronavirus - Thailand (ex-China). Jan 14, 2020. Available online: http://www.who.int/csr/don/14- january-2020-novel-coronavirus-thailand/en/

5. WHO. Novel coronavirus - Japan (ex-China). Jan 17, 2020. Available online: http://www.who.int/csr/don/17january-2020-novel-coronavirus-japan-ex-china/en/

6. WHO. Novel coronavirus - Republic of Korea (ex-China). Jan 21, 2020. Available online: http://www.who.int/csr/ don/21-january-2020-novel-coronavirus-republic-ofkorea-ex-china/en/

7. CDC. First travel-related case of 2019 novel coronavirus detected in United States. Jan 21, 2020. Available online: https://www.cdc.gov/media/releases/2020/p0121-novelcoronavirus-travel-case.html

8. National Health Commission of People's Republic of China. Diagnosis and treatment of 2019 novel coronavirus pneumonia (5th trial version). Feb 4, 2020. Available online: http://www.nhc.gov.cn/yzygj/s7653p/202002/3b09 b894ac9b4204a79db5b8912d4440/files/7260301a393845fc 87 fcf6dd52965ecb.pdf

9. Chen N, Zhou M, Dong X, et al. Epidemiological and clinical characteristics of 99 cases of 2019 novel coronavirus pneumonia in Wuhan, China: a descriptive study. Lancet 2020;395:507-13.

10. Huang C, Wang Y, Li X, et al. Clinical features of patients infected with 2019 novel coronavirus in Wuhan, China. Lancet 2020;395:497-506.

11. Chan JF, Yuan S, Kok KH, et al. A familial cluster of pneumonia associated with the 2019 novel coronavirus indicating person-to-person transmission: a study of a family cluster. Lancet 2020;395:514-23.

12. Zhu N, Zhang D, Wang W, et al. A Novel Coronavirus from Patients with Pneumonia in China, 2019. N Engl J Med 2020;382:727-33.

13. Assiri A, Al-Tawfiq JA, Al-Rabeeah AA, et al. Epidemiological, demographic, and clinical characteristics of 47 cases of Middle East respiratory syndrome coronavirus disease from Saudi Arabia: a descriptive study. Lancet Infect Dis 2013;13:752-61.

14. Lee N, Hui D, Wu A, et al. A major outbreak of severe acute respiratory syndrome in Hong Kong. N Engl J Med 2003;348:1986-94.

15. Guan W, Ni Z, Hu Y, et al. Clinical characteristics of 2019 novel coronavirus infection in China. N Engl J Med 2020. doi: 10.1056/NEJMoa2002032.

Cite this article as: Li Y, Xu S, Du T, Xu J, Li Y, Yu X, Zhu H. Clinical features of 2019 novel coronavirus infection in Beijing. J Thorac Dis 2020;12(5):2563-2568. doi: 10.21037/jtd.2020.03.33 